American Journal of Applied Sciences 5 (4): 296-300, 2008

ISSN 1546-9239

(C) 2008 Science Publications

\title{
The Effect of Corner Radii and Part Orientation on Stress Distribution of Cold Forging Die
}

\author{
Ahmad Baharuddin Abdullah, Kam Shwu Ling and Zahurin Samad \\ School of Mechanical Engineering, Universiti Sains Malaysia \\ Engineering Campus, 14300 Nibong Tebal \\ Penang, MALAYSIA
}

\begin{abstract}
One of the most critical problems in cold forging is the huge stresses generated from the deformation of metal leads to die failure. The distribution of stresses mainly depends on geometry of the die. An approach to optimal design in cold forging die geometry and orientation are presented in this paper. The impression cold forging dies of the Universal joint was generated using three-dimensional CAD modeling software, SolidWorks. This CAD modeling software coupled with FEA tools, COSMOSWorks. The paper emphasizes on effect of the corner radius and dies orientation on stress distribution.
\end{abstract}

Keywords : Cold forging die, corner radii, orientation, stress distribution

\section{INTRODUCTION}

Cold forging is one of the most widely used metal forming processes, where a bulk of material is compress at room temperature with no heating of the initial slug or inter-stages to produced the desired shape and size. The process produces greater dimensional accuracy than hot forming, and does not produce scale. However, the plastic flow characteristics of the workpiece require higher forging pressures and at the same time induce stress onto the die ${ }^{[1]}$. As a result, this will affect performance of the die including service life and quality of finished parts. There are many researches show that this problem can be solved by applying appropriate methods either by improving the cold forging process or by improving the die design. The purpose is the same, which to reduce the stress on die that resulted during the forging operation.

The important factors in the process design of cold forging are the shape of pre-form and the number of pre-forgings. Process conditions and sequence of process design are very important in improving the forging process. Process condition such as the stressstrain relationship of the billet and die materials, the friction between the billet and the die, etc ${ }^{[2]}$. The resulted stress on die can be reduced by improving the die design. For example:
Improve the die material properties; Usually, die materials must be hardened to withstand severe service conditions, but also need to have enough ductility to prevent their cracking and brittle fracture.

ii) Design the flash at appropriate location with proper size and shape; normally, flash is used to release the working pressure during forging operation.

Numbers of research have been done in reducing stress such as by dividing the process into multi-steps

[3]. Some of them emphasis on introducing new design approach such as pre-chamfering, spread extrusion and relief axis ${ }^{[4]}$ and double tapered insert and split insert design ${ }^{[5]}$. Stress can also be reduced by focusing on the highest loaded zone and suggest several solution such as by increasing the transition radii [6]. Many parameters have been consider such as land width, petal angle and rake angle are taken into consideration ${ }^{[7]}$ and changing the die material ${ }^{[5]}$. Catastrophic failure is due tensile stress especially at stress concentration region of the die i.e. at fillets and corner and to avoid this type of failure two recommendations are suggested i.e. by changing the die profile or use pre-stress elements ${ }^{[8]}$. In

Corresponding Author:

Ahmad Baharuddin Abdullah, School of Mechanical Engineering, Universiti Sains Malaysia, Engineering Campus, 14300 Nibong Tebal, Penang, MALAYSIA, Tel: +604-5996332, Fax: +604-5941025 
order to simplified the experimental which is very expensive, a dimensional analysis based on similarity law has been derived to study stress distribution on forging die. The results are verified by conducting experiment ${ }^{[9]}$.

Main objectives of this study are to investigate the effect of corner radius of the die and cavity orientation on resulted stress. The paper begins with the introduction and then followed by methodology used in this research. After the dies are model and analyze, then the results are discussed and paper end with conclusion and future works.

\section{METHODOLOGY}

In this study AISI type A2 tool steel is used as die material with hardness of HRC 62. Moreover, the compressive strength that are absolutely high also encourage this material served as tooling purpose in cold forging process. A typical scaling factor to account for shrinkage is $2 \%$ as shown in Fig. 1. The parts will shrink uniformly in all directions due to densification of the metal powder. A three-dimensional solid model of a cold-forged universal joint is generated in SolidWorks. The solid model of the Universal joint is used to create cavities in three-dimensional models of impression cold forging dies. The parameter study is the die orientation and corner radii.

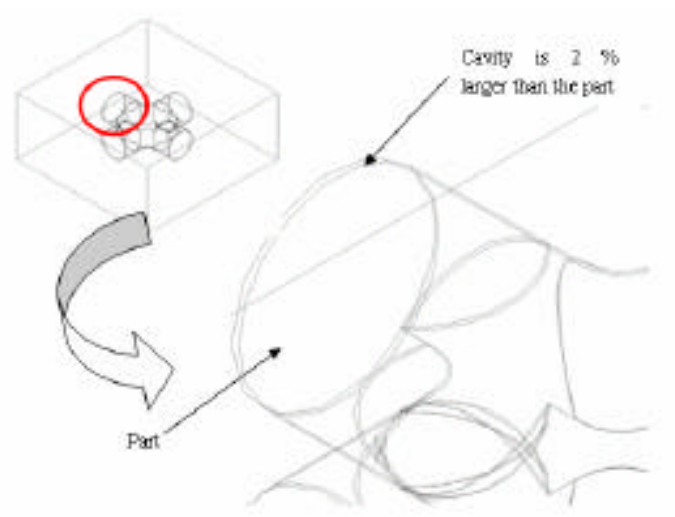

Fig. 1: The scaling factor of $2 \%$ in die design

\section{DIE MODELING}

In tool design, an appropriate material must be selected, where the strength of physical, chemical, mechanical, electrical and thermal properties must take into consideration. The material properties of the tool steel are listed in Table 1.
Table 1: Properties of AISI type A2 Tool Steel

\begin{tabular}{ll} 
Properties & Value \\
Density, ? & $0.007861 \mathrm{~g} / \mathrm{mm}^{\wedge} 3$ \\
Color & gray \\
Compressive Strength & $2861.324 \mathrm{~N} / \mathrm{mm}^{\wedge} 2$ \\
Compressive yield Strength & $2137.375 \mathrm{~N} / \mathrm{mm}^{\wedge} 3$ \\
Young's Mod. & $203395 \mathrm{~N} / \mathrm{mm}^{\wedge} 3$ \\
Hardness & $62 \mathrm{HRC}$ \\
Poisson's Ratio, ? & 0.30 \\
Shear Modulus, G & $78000 \mathrm{~N} / \mathrm{mm}^{\wedge} 2$ \\
\hline
\end{tabular}

The scaling factor is the amount the material in the mold shrinks or expands as it solidifies. The scaling factor depends on the type of material used and the shape of the mold, and is expressed as a percentage of the linear size (not volume) of the design part. The software scales the cavity by the specified scaling factor, using this formula: Cavity size $=$ part size $*(1+$ scaling factor/100). Theoretically, different die configurations will result in different stress pattern and provide different lifetime. This due to the different load pattern is applied on the surface of the die. Therefore, the solid model of the universal joint is used to generate die in different configuration in terms of cavity orientation is the main focus of the study.

Load calculation: Before the simulation, the forging load needs to be calculated. The value of friction factor, cavity flow stress and the die geometry need to be obtained and inserted into the Slab equation. The cavity flow stress is equals to the yield strength of the forging material (not the die material), and the geometry of the die after scaling. Therefore, in this project, there are 21 different sets of dies will be analyzed using the COSMOSWorks. In the calculation, it is assumed that the cavity has a rectangular shape as shown in Fig. 2

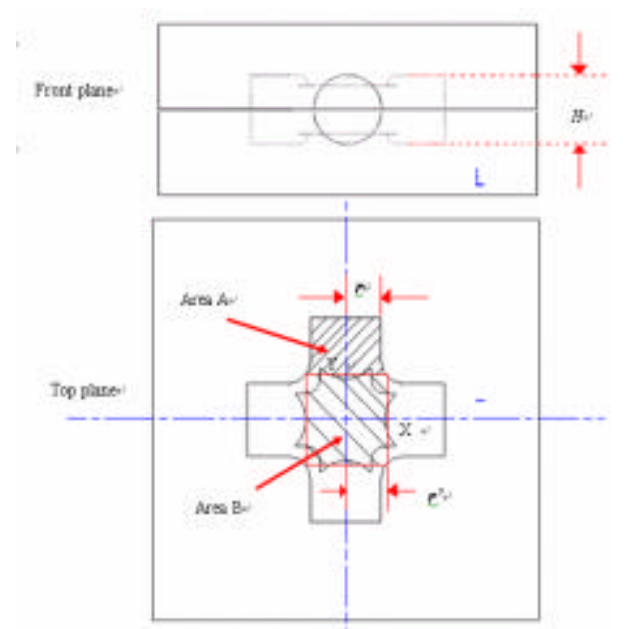

Fig. 2: Front and top cross-section area of the die 
For a given $r=16.32 \mathrm{~mm}, r^{\prime}=19.31 \mathrm{~mm}, H=$ $32.64 \mathrm{~mm}, m=1.0$ for die tool and flow stress, $\sigma$ for this case $350 \mathrm{MPa}$ and the resulted forming load generate is $p_{t a}=318803 P a$ or in ton equivalent to 0.29 ton.

Die Configuration: In this study three orientations are considered. Figure 3 shows the different orientation of the part resulting in different die cavity orientation of horizontal (0 degree), vertical (90 degree) and 45 degrees. Figure 4 show the edge consider of each die. Minimum recommended corner radius for die design is $1 \mathrm{~mm}$. Therefore, corner radii for each orientation are fixed between 1 to $3.5 \mathrm{~mm}$.

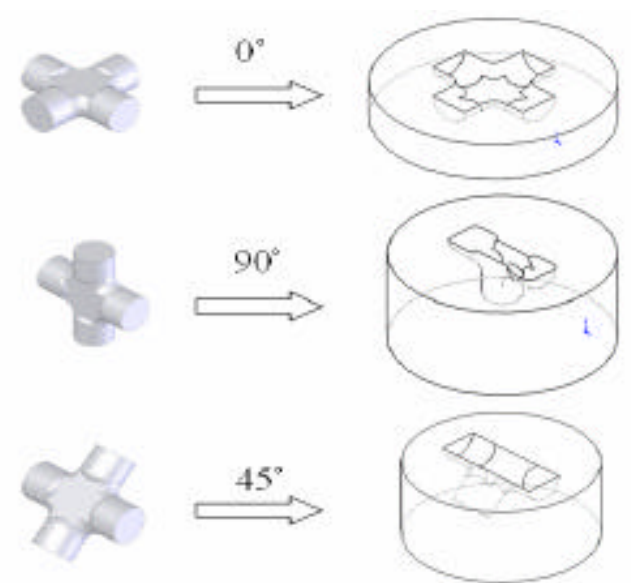

Fig. 3: Three different $U$ joint orientations with its lower die respectively

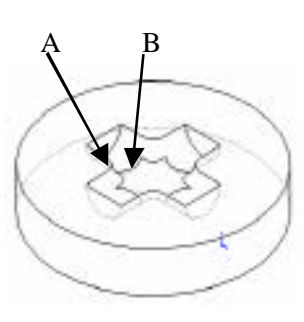

(a)

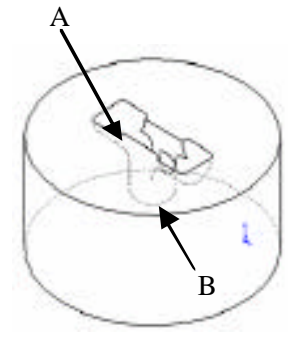

(b)

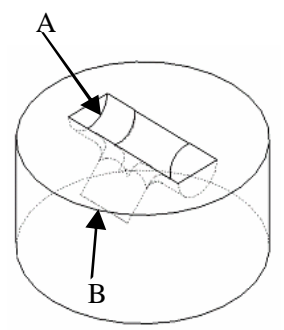

(c)
Fig. 4: Forging die with different corner radii consider in the analysis for each of the orientation of, (a) horizontal, (b) vertical and (c) 45 degree die

\section{RESULTS AND DISCUSSION}

In static study on the cold-forging die, a stress analysis is developed using the COSMOSWorks software. Figure 5 show the resulted stress distribute on the die during forging operation affected by the corner radius and for a case of horizontal die orientation. Figure 6 outlined the resulted Von Misses stress for range of corner radii. The result shows that the optimal corner radius is at $3 \mathrm{~mm}$, where the stress is the minimum. From the results shown in Fig. 6, the stress is decreasing when the corner radius increasing. Figure 7 the result shows a similar trend, where the stress will continue reduced when the corner radius is increased. From Fig. 8, it is clear that the stress generated in die with corner radii $3.5 \mathrm{~mm}$ is higher than stress generated in die with sharp corner. When the corner radius continues to increase, the stress generated will continue to be reduced until it become lower than the stress on sharp corner die. However, it is not practical to use corner radius that is too large, where the final forging may need more finishing operations or may not accurate in final dimension. From the results shown in Fig. 9, from overall, the stress is decreasing with the increasing in corner radius. However, there is no significant improvement in stress reduction if compare to sharp corner die (original). It can be concluded that, the stress trend is same with the stress trend obtained from vertically oriented die.

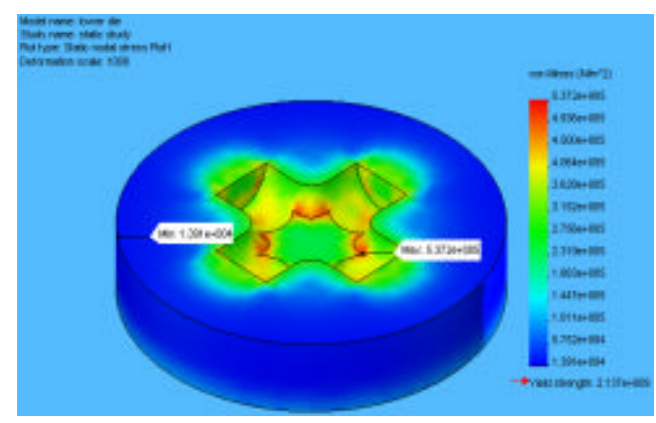

Fig. 5: Stress plot of die with sharp corner radius

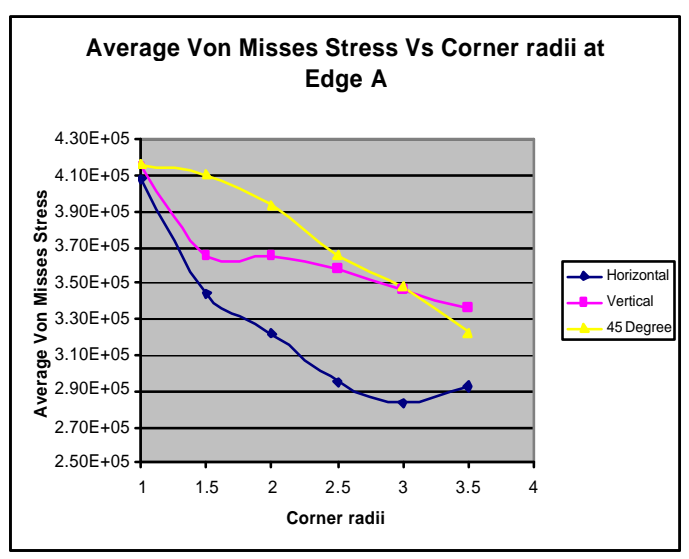

Fig. 6: The result for edge A at different orientations 


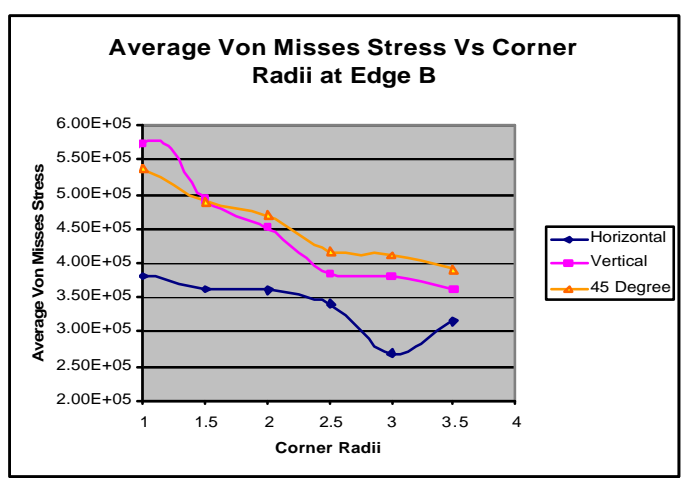

Fig. 7: The result for edge $B$ at different orientations

From the Fig. 8, the optimal die orientation is horizontally oriented, which resulted in minimum stress on the die with given range of corner radius. Whereas the 45 degree oriented die design generated the highest stress. The result is show in Fig. 9 maximum displacement set of data is considered. Result from deformation analysis shows that, the deformation pattern of the die set. Result from deformation analysis shows that the deformation of the die is decreasing as the corner radius is increasing for all three different cavity orientations in die. However, the deformation for the vertical oriented die increased when the corner radius exceed $3.0 \mathrm{~mm}$, where the deformation is minimum for die with corner radius of $3.0 \mathrm{~mm}$.

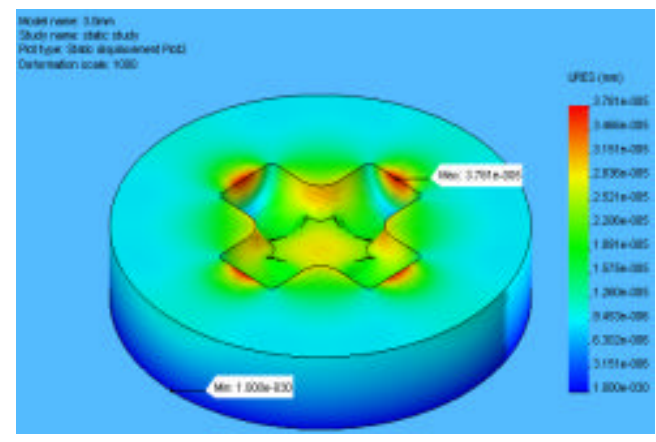

(a)

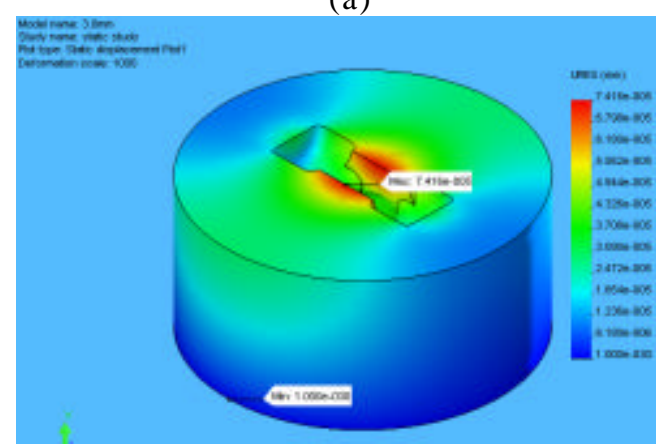

(b)

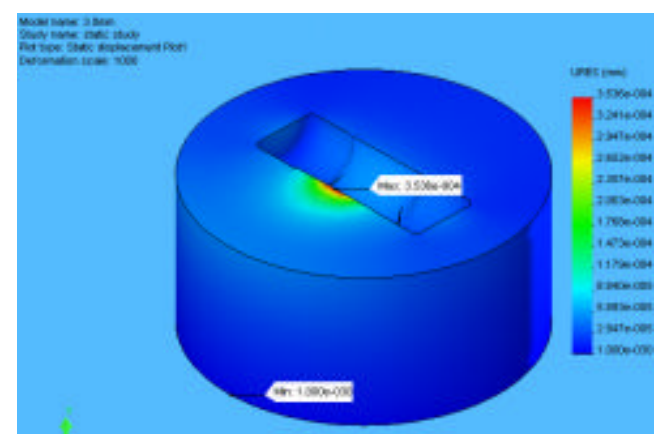

(c)

Fig. 8: Displacement plot of die with $3.0 \mathrm{~mm}$ corner radius

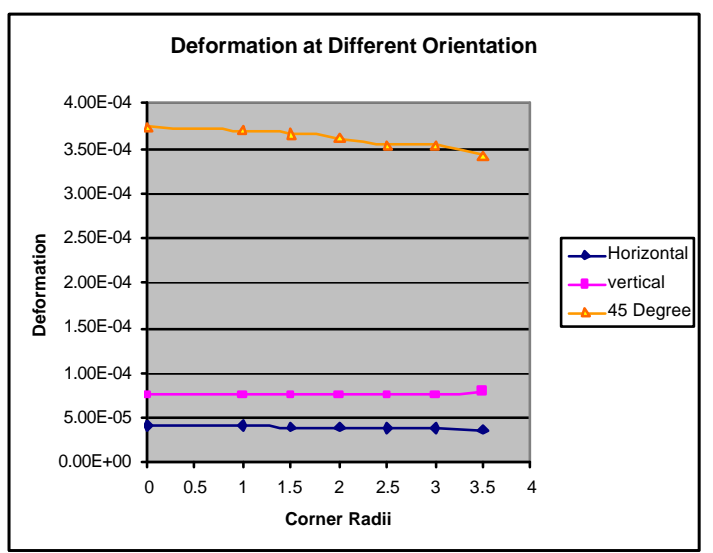

Fig. 9: Maximum displacement plot for each corner radius respectively

\section{CONCLUSION AND FUTURE WORKS}

From the study carried out, it can be concluded that, the changing in corner radius can affect the stress level generated on the die. Where there is a range that the stress level will drop even though the corner radius is increasing. After studied twenty-one different design of dies, the optimal design is the horizontally oriented die with corner radius of $3 \mathrm{~mm}$. This design not only induced in lowest stress level during the forging operation, but also causing minimum deformation on die, where the structure of the die can return to its original position after removing the load exerted. For future works, the result of the analysis will be verified by conducting experimental method.

\section{ACKNOWLEDGEMENT}

The authors would like to thank the School of Mechanical Engineering and Universiti Sains Malaysia 
for their cooperation and Ministry of Science, Technology and Innovation (MOSTI) for fund provided.

\section{REFERENCES}

1. Altan T, Oh S. K. and Gegel, H. L., 1983, Metal forming: Fundamentals and applications, American Society for Metals.

2. Hallström, J. 2000. Influence of friction on die filling in counterblow hammer forging, J. Material Processing Technology, 108 (1): $21-25$.

3. Xia, Z. S., T. Muramatsu, C. C. Mun and S. Tong, 2001. Precision forging of small net-shape component - reduction of forming pressure through tool design, SIMTech Technical Report, PT/01/039/PMF.

4. Tong, S., Muramatsu, T., Mun, C. C., Xia, A. S. and Enggalhardjo, M. 2001, Precision Cold Forging - Innovative methods for working pressure reduction, SIMTech Technical Reports, PT/01/042/PMF.

5. Vazquez, V., Hannan, D. and Altan, T., 2000, Tool life in cold forging - an example of design improvement to increase service life, J. of Material Processing Technology, 98(1): 90-96.
6. McCormack, C. and Monaghan, J., 2001, A finite element analysis of cold-forging dies using twoand three-dimensional models, J. of Material Processing Technology, 118(1-3): 286-292.

7. Mc Cormack, C. and John Monaghan, 1998, An Investigation into the Reduction of Tool Stresses Caused during a Cold Forging Process by Altering the Corner Fillet Geometry, Proceeding of the Irish Manufacturing Conference, IMC 15, 55-64.

8. Koç, M. and M. A. Arslan, 2003. Design and finite element analysis of innovative tooling elements (stress pins) to prolong die life and improve dimensional tolerances in precision forming processes, J. of Materials Processing Technology, 142(3): 773-785.

9. Navarrete, J, M. E. Noguez, J. Ramirez, G. Salas and T. Robert, 2001, Die Forging Stress Determination: A Dimensional Analysis Approach, Journal of Manufacturing Science and Engineering, 123: 416-419. 